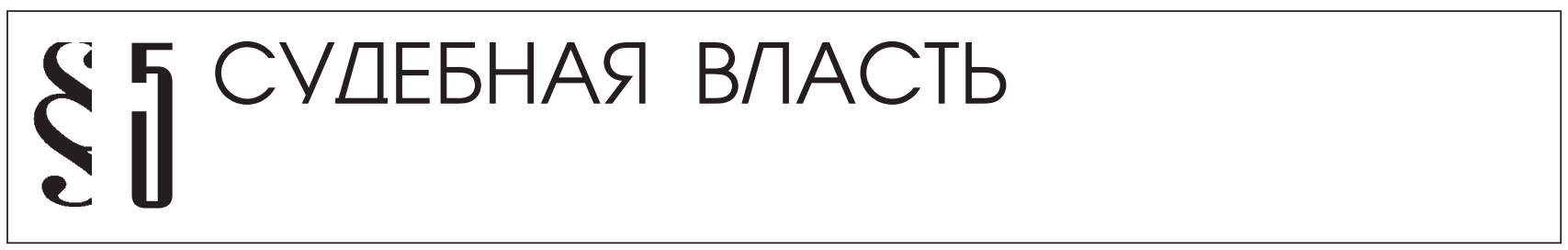

Ратушная Б.П.

\title{
ПРОБЛЕМЫ МОТИВИРОВАННОСТИ СУДЕБНЫХ РЕШЕНИЙ В УКРАИНЕ
}

\begin{abstract}
Аннотация: В статье рассматриваются теоретические и законодательные проблемы мотивированности судебных решений в Украине. На основании анализа украинского проиессуального законодательства, теоретических наработок по указанному вопросу и прецедентной практики Европейского Суда по правам человека обосновываются положения о том, что мотивированность судебных решений - наряду с их законностью и обоснованностью - является важным требованием к качеству судебных решений. Соблюдение этого требования свидетельствует о справедливости судебного разбирательства в ијелом и процесса установления фактических обстоятельств дела в частности. Обосновываются положения о том, что мотивированность судебного акта связана с вопросами изложения мотивов как результатов логико-мыслительной деятельности, на основании которых суд пришел к определенным выводам. Констатируется, что в судебно-процессуальном законодательстве Украины, кроме Уголовного процессуального кодекса, отсутствует нормативное закрепление самостоятельного требования мотивированности судебных решений. В связи с этим предлагается внести соответствуюшие изменения в проиессуальное законодательство Украины, кроме УПК Украины, где такое закрепление существует.
\end{abstract}

Ключевые слова: Юриспрудениия, правоприменение, требования, законность, обоснованность, мотивированность, решения, практика, законодательство, суд

ульминационным моментом в осуществлении правосудия является, как известно, принятие судебного решения. В этом правоприменительном акте отражается результат всего судебного процесса по определенному делу, сконцентрированы выводы о процессуальной деятельности всех его участников и дается ответ на ключевые запросы сторон. В связи с этим принципиальное значение имеет вопрос о требованиях, которые предъявляются к судебным решениям. Украинский законодатель традиционно предусматривает два обязательных требования к судебным решениям - их законности и обоснованности

Решение считается законным тогда, когда суд решил дело в соответствии с нормами материального права, подлежащими применению к данным правоотношениям, правильно истолковав эти нормы.

Обоснованным признается решение, принятое на базе полностью и всесторонне выясненных обстоятельств, на которые стороны ссылаются как на основание своих требований и возражений, подтвержденных доказательствами, которые были исследованы в судебном заседании и отвечают требованиям закона об их относимости и допустимости, или обстоятельств, не подлежащих доказыванию, а также если решение содержит исчерпывающие выводы суда, которые отвечают установленным на основании достоверных доказательств обстоятельствам, имеющим значение для разрешения дела' ${ }^{1}$. Но кроме этих требований, во многих странах (например, Нидерландах, Бельгии) на суд возлагается обязанность еще и мотивировать принимаемые им решения 2 .

Европейский суд по правам человека (далее - Суд, ЕСПЧ) для обеспечения справедливого судебного разбирательства также подчеркивает важность принятия судами не только законных и обоснованных, но также и мотивированных судебных актов ${ }^{3}$. Правовые позиции ЕСПЧ по этому вопросу весьма значимы для любого судебного правоприменения. В частности, в решении по делу «Руис Тория против Испании» от 9 декабря 1994 г. Суд отмечал, что «в соответствии с установленным преце-

\footnotetext{
${ }^{1} \mathrm{O}$ судебном решении в гражданском деле: постановление Пленума Верховного Суда Украины от 18.12.2009 N 14 // http://zakon. rada.gov.ua.

${ }^{2}$ Николайченко $О$. О значении мотивировочной части судебного решения / О. В. Николайченко // Международная заочная научнопрактическая конференция «Вопросы современной юриспруденции» (Россия, г. Новосибирск, 6 февраля 2012г.) /http://sibac.info/ index.php/

${ }^{3}$ Манукян В. Международная защита прав человека: право, прецеденты, коментарии: научно-практичесое пособие. / В. И. Манукян - К.: Истина, 2010. - С. 177.
} 
дентным правом, которое отражает принцип надлежащего отправления правосудия, в решениях судов должны быть надлежащим образом указаны основания, по каким они были приняты. Пункт 1 статьи 6 Конвенции обязывает судебные инстанции указывать мотивацию принимаемых ими решений, но этот пункт нельзя толковать как таковой, который обязывает предоставлять подробный отчет по каждому аргументу. То, в какой степени должна выполняться обязанность указывать мотивировку, зависит от характера решения» ${ }^{4}$. И хотя национальные суды пользуются ограниченным правом принятия решений в вопросе выбора доводов по конкретному делу и приобщении доказательств достоверности утверждений сторон, эти органы обязаны указать основания для своих действий, изложив мотивы этих решений (дело «Суоминен против Финляндии» от 1 июля 2003$)^{5}$.

Важное значение мотивированности решения состоит в том, что оно демонстрирует сторонам, что их позиции были выслушаны. Кроме этого, мотивированное решение создает лучшие возможности каждой стороне обжаловать его, а апелляционной инстанции - эффективно его пересмотреть. Важно и то, что изложение мотивированного решения является единственной возможностью для общества следить за осуществлением правосудия (дело «Хирвисаари против Финляндии» от 27 сентября 2001 г. $)^{6}$. Таким образом, проблема мотивированности судебных актов является крайне актуальной. Как справедливо отмечалось в литературе, «наличие мотивов позволяет уяснить логику судебного акта, понять причины, по которым суд сделал те или иные выводы, и защитить участникам процесса свои права при обжаловании решения» ${ }^{7}$. Следует согласиться с тем, что «оставление в силе судейских ляпсусов невозможно без аргументов, но обосновать, что «черное»- это«белое», мотивировано оправдать очевидную ошибку без демонстрации собственного невежества нельзя» ${ }^{8}$. Итак, мотивированность судебного решения помогает четче понять

${ }^{4}$ Де Сальвиа М. Прецеденты Европейского Суда по правам человека. Руководящие принципы судебной практики, относящиеся к Европейской конвенции о защите прав человека и основних свобод. Судебная практика с 1960 по 2002 г. / М. Де Сальвиа. - СПб. : Издательство «Юридический центр Пресс», 2004 - С. 420.

${ }^{5}$ Султанов А. О проблеме мотивированности судебных актов, через призму Постановлений Европейского Суда по правам человека / А. Р. Султанов // Арбитражное право. - 2007. - № №178 (1952).

${ }^{6}$ Султанов А. О проблеме мотивированности судебных актов, через призму Постановлений Европейского Суда по правам человека / А. Р. Султанов // Арбитражное право. - 2007. - № №178 (1952).

${ }^{7}$ Ярков В. Комментарии к АПК РФ / под. ред.. В. В. Яркова. - М., 2003. - C. 29.

${ }^{8}$ Поляков Ю. К вопросу о независимости суда / Ю. Н. Поляков // «Государство и право». - 2000. - №10. - С. 85 логику суда при принятии решения, и в результате этого уяснить насколько законным и обоснованным является это решение.

\section{Представления о мотивированности судебных решений в теории судебного процесса}

До недавнего времени постсовецкая процессуальноправовая наука уделяла недостаточное внимание вопросу мотивированности судебных решений. В научной же литературе советского периода мотивированность как самостоятельное требование к судебному решению либо вообще исключалась, либо рассматривалась как составная часть обоснованности или законности судебного решения.

Одной из первых мотивированность как самостоятельное требование к судебному решению, существующее наряду с законностью и обоснованностью, отметила М. Викут. С ее точки зрения мотивированность не тождественна требованию обоснованности, поскольку означает, что выводы, к которым пришел суд, должны основываться на доказательствах, а мотивированность означает наличие в судебном акте ссылки на доказательства, их оценку, толкование судом правовой нормы, применяемой при квалификации спорных правоотношений9.

Современные ученые расходятся в понимании мотивированности. Прежде всего следует отметить, что под мотивом судебного решения понимают соображения, приводимые судом в мотивировочной части судебного решения для обоснования выводов по каждому из вопросов, которые должны быть решены при принятии решения $^{10}$. Высказывается мнение, согласно которому «соблюдение требования мотивированности, которое предъявляется к судебному решению, нельзя рассматривать как процессуальное средство, обеспечивающее достижение обоснованности судебного решения. Мотивированность и обоснованность соотносятся как форма и содержание. Наличие соответствующей формы не определяет ее содержания. Таким образом, по мнению И. Фильченко, требования мотивированности и обоснованности сливаются в одно целое. Но все же доминирующими оказываются взгляды о том, что «мотивированность является самостоятельным требованием, которое

\footnotetext{
${ }^{9}$ Викут M. Законность и обоснованность актов социалистического правосудия как главное условие выполнения задач гражданского судопроизводства / М. А. Викут // Цивилистические проблемы правового статуса личности в социалистическом обществе .-Саратов, 1982. - С. 124. Пономаренко В. А. Мотивированность судебного решения в гражданском и арбитражном процессе : автореф. дисс.. на соискание степени канд.. юрид. наук : 12.00.15, Москва, 2007.

${ }^{10}$ Фильченко И. Г. Процессуальные гарантии принятия обоснованного судебного решения в гражданском процессе: автореф. дисс.. на соискание степени канд.. юрид. наук. 12.00.15, Воронеж , 2010.
} 


\section{Право и политика $6(162) \cdot 2013$}

необходимо отличать от обоснованности судебного решения. Разграничивать эти требования надо, исходя из практического значения мотивированности, которая заключается в необходимости акцентировать внимание суда на действиях по мотивации решения, обязанности указать в решении совокупность мотивов, которые бы показывали, какую умственную, логико-практическую деятельность совершил суд при принятии решения. Поэтому мотивированность - это требование указывать письменно в решении логические выводы суда о фактах и правоотношения ${ }^{11}$. С. Загайнова также считает мотивированность самостоятельным требованием к судебному решению, однако отмечает, что сведение мотивирования только к выводам о фактах и правоотношениях сужает действие этого требования, ведь в этом случае остается без внимания правовая квалификация спора, который рассматривается. Указанный автор отмечает, что «законность и обоснованность судебного акта обусловлены либо зависят от надлежащего уровня мотивации. Мотивация это отражение логической умственной деятельности суда при реализации в конкретном судебном акте требований законности и обоснованности. Эти два требования будут иметь надлежащий характер только тогда, когда в них будет четко отражен алгоритм соображений. Именно этот алгоритм судебной мыслительной деятельности по вопросам применения права, оценки фактических обстоятельств дела, оценки доказательств и является таким качеством судебного акта как мотивированность» ${ }^{12}$. По мнению А. Толочко, мотивированность «будучи правовым требованием, с одной стороны отражает связь между фактическими обстоятельствами дела, установленными судом, и выводами; устраняет разрозненность доказательственной информации; позволяет выявить противоречия в исследуемых доказательствах» ${ }^{13}$. Другие авторы также полагают, что мотивированность является сущностной характеристикой содержания решения, которое связывает правовые выводы суда с установленными в судебном разбирательстве юридическими фактами и последовательно отражает процесс формирования убеждения судьи в правовой сути дела ${ }^{14}$. Недаром в ан-

${ }_{11}$ Лебедь К. Решения арбитражного суда / К. А. Лебедь. - М., 2005. - C. 80-83.

12 Загайнова С. Судебные акты в механизме реализации судебной власти в гражданском и арбитражном процессе // С. К. Загайнова. - М. : Волтерс Клувер. - 2007. - С. 299.

13 Толочко А. Н. Роль мотивировки в обеспечении законности, обоснованности и справедливости актов социалистического правосудия, выносимых судом первой инстанции по уголовным делам: автореф. дисс.. на соискание степени канд.. юрид. наук, Харьков, 1985. - С. 9.

${ }^{14}$ Афанасьев С. Ф. Право на справедливое судебное разбирательство: теоретико-практическое исследование влияния Европейской Конвенции о защите прав человека и основных свобод на россий- глосаксонской системе права именно мотивы принятия решения образуют судебный прецедент, в котором отражается логическая, мыслительная деятельность судьи по рассматриваемому им делу.

В литературе выделяют несколько видов мотивов судебного решения. Так, по мнению О. Каплиной, решение должно основываться на фактических и правовых мотивах. Фактические мотивы, с точки зрения этого автора, должны отражать анализ исследованных в судебном рассмотрении источников доказательств с точки зрения их относимости, допустимости, достаточности, достоверности. Правовые мотивы, которые тоже следует приводить в решении, представляют собой казуальное толкование норм права. Учитывая важную правовую и социальную роль судебного акта в его мотивировочной части следует приводить мотивы, согласно которым на основании толкования нормы права и личного убеждения судья считает необходимым применить ту или иную норму права ${ }^{15}$.

По мнению В. Пономаренко, мотивы судебного решения следует классифицировать на фактические, правовые и моральные $e^{16}$. Представляется, что выделять моральные мотивы как отдельный вид нецелесообразно, ведь в таком случае напрашивается вывод о том, что фактические и правовые мотивы не являются моральными, нравственными. Юридическое значение могут иметь только фактические и правовые мотивы, а приведение в решении моральных мотивов может иметь лишь определенное воспитательное воздействие на участников дела, но не вызовет каких-либо правовых последствий.

Основные выводи. Учитывая вышеизложенное, считаем целесообразным присоединиться к позиции, согласно которой мотивированность является самостоятельным требованием к судебному решению. Мотивированность судебного акта связана с вопросами изложения мотивов как результатов логико-мыслительной деятельности, на основании которых суд пришел к определенным выводам. Мотивы являются логическим мостиком между вопросами права и факта и отражают личностное видение судьи обстоятельств дела. Мотивированность решения делает его понятным и убедительным, помогает осуществить и упростить проверку правомерности решения. Мотивированное решение показывает, что правосудие

ское гражданское судопроизводство: автореф. дис.. на соискание ученой степени доктора юрид. наук, Саратов, 2010.

${ }^{15}$ Капліна О. В. Правозастосовне тлумачення судом норм кримінально-процесуального права. - автореф. дис.. на здобуття наукового ступеня доктора юридичних наук за спеціальністю 12.00.09 - Національна юридична академія України імені Ярослава Мудрого, Харків, 2009.

${ }^{16}$ Пономаренко В. А. Мотивированность судебного решения в гражданском и арбитражном процессе : автореф. дисс.. на соискание степени канд.. юрид. наук : 12.00.15, Москва, 2007. 
свершилось, поскольку, по словам лорда Хьюарта, «правосудие должно не только свершиться, оно должно свершиться так, чтобы каждый мог видеть: правосудие очевидно и безусловно свершилось» ${ }^{17}$.

Следует отметить, что украинское процессуальное законодательство не выделяет такого требования к судебному решению как мотивированность. Исключением является лишь действующий Уголовно-процессуальный кодекс Украины, где указано, что судебное решение должно быть законным, обоснованным и мотивированным. Устанавливается, что мотивированным является решение, в котором приведены надлежащие и достаточные мотивы и основания его принятия (ч. 4 ст. 370 УПК).

Однако нельзя утверждать, что другие процессуальные кодексы Украины вообще игнорируют требование мотивированности судебного решения. Например, Гражданский процессуальный кодекс Украины приурочивает идею мотивирования решения только применительно к оценке доказательств, поскольку согласно статье 212 Гражданского процессуального кодекса результаты такой оценки доказательств суд отражает в решении, в котором приводятся мотивы их принятия или отказа в принятии. Хозяйственный процессуальный кодекс Украины и Кодекс Административного Судопроизводства Украины такой формулировки не содержат, хотя во всех них предусмотрено, что составной частью содержания судебного решения должна быть мотивировочная часть (ст. 215 ГПК, ст. 163 КАС, ст. 374 УПК, ст. 84 ХПК).

Опосредствованное признание законодателем Украины важности мотивировать решение прослеживается в процедуре принятия судебного решения, поскольку в зависимости от сложности дела составление полного решения с мотивировочной частью может быть отложено на срок не более пяти дней со дня окончания рассмотрения дела, но вступительную и резолютивную части суд должен провозгласить в том же заседании (ч. 3 ст. 209 ГПК, ч. 3 ст. 160 КАС, ст. 85 ХПК).

Таким образом, мотивированность судебных решений, наряду с их законностью и обоснованностю, является важным требованием, соблюдение которого свидетельствует о справедливости судебного разбирательства в целом и процесса установления фактических обстоятельств дела в частности.

Учитывая важность для осуществления справедливого правосудия мотивированности судебных решений, а также принимая во внимание правовые позиции ЕСПЧ, нормативное закрепление этого требования в процессуальных кодексах Украины представляется настоятельно необходимым.

\footnotetext{
${ }^{17}$ Манукян В.И. Международная защита прав человека: право, прецеденты, комментарии: научно-практическое пособие. К.: Истина, 2010. - С. 169. 480 с.
}

\section{Библиография:}

1. О судебном решении в гражданском деле: постановление Пленума Верховного Суда Украины от 18.12.2009 г. N 14. // http://zakon.rada.gov.ua.

2. Николайченко О. О значении мотивировочной части судебного решения / О. В. Николайченко // Международная заочная научно-практическая конференция «Вопросы современной юриспруденции (Россия, г. Новосибирск, 6 февраля 2012г.) /http://sibac. info/index.php/

3. Манукян В. Международная защита прав человека: право, прецеденты, коментарии: научно-практичесое пособие. / В. И. Манукян - К.: Истина, 2010. - 477 с.

4. Де Сальвиа М. Прецеденты Европейского Суда по правам человека. Руководящие принципы судебной практики, относящиеся к Европейской конвенции о защите прав человека и основних свобод. Судебная практика с 1960 по 2002 г. / М. Де Сальвиа. - СПб. : Издательство «Юридический центр Пресс», 2004. -1240 c.

5. Султанов А. О проблеме мотивированности судебных актов, через призму Постановлений Европейского Суда по правам человека / А. Р. Султанов // Арбитражное право. - 2007. - № №178 (1952)./ http:// www.yurclub.ru/docs/arbitration/.

6. Ярков В. Комментарий к АПК РФ / под. ред.. В. В. Яркова. М.: БЕК, 2003.

7. Поляков Ю. К вопросу о независимости суда / Ю. Н. Поляков // «Государство и право». - 2000. - №10. - С. 85.

8. Викут М. Законность и обоснованность актов социалистического правосудия как главное условие выполнения задач гражданского судопроизводства / М. А. Викут // Цивилистические проблемы правового статуса личности в социалистическом обществе . - Саратов, 1982. - С. 124.

9. Пономаренко В. А. Мотивированность судебного решения в гражданском и арбитражном процессе : автореф. дисс.. канд.. юрид. наук. Москва, 2007.

10. Фильченко И. Г. Процессуальные гарантии принятия обоснованного судебного решения в гражданском процессе: автореф. дисс.. канд.. юрид. наук. Воронеж, 2010.

11. Лебедь К. Решения арбитражного суда / К. А. Лебедь. - М., 2005. - 116 c.

12. Загайнова С. Судебные акты в механизме реализации судебной власти в гражданском и арбитражном процессе // С. К. Загайнова. - М. : Волтерс Клувер. $-2007 .-400 \mathrm{c}$.

13. Толочко А. Н. Роль мотивировки в обеспечении законности, обоснованности и справедливости актов социалистического правосудия, выносимых судом 


\section{Право и политика 6 (162) • 2013}

первой инстанции по уголовным делам: автореф. дисс.. канд.. юрид. наук, Харьков, 1985.

14. Афанасьев С. Право на справедливое судебное разбирательство: теоретико-практическое исследование влияния Европейской Конвенции о защите прав человека и основных свобод на российское гражданское судопроизводство: автореф. дис.. доктора юрид. наук, Саратов, 2010.

15. Капліна О. I. Правозастосовне тлумачення судом норм кримінально-процесуального права: автореф. дис.. доктора юридичних наук, Харків, 2009.

\section{References (transliteration):}

1. Nikolaychenko O. O znachenii motivirovochnoy chasti sudebnogo resheniya / O. V. Nikolaychenko // Mezhdunarodnaya zaochnaya nauchno-prakticheskaya konferenciya «Voprosy sovremennoy yurisprudencii (Rossiya, g. Novosibirsk, 6 fevralya 2012g.) /http://sibac. info/index.php/

2. Manukyan V. Mezhdunarodnaya zaschita prav cheloveka: pravo, precedenty, komentarii: nauchno-praktichesoe posobie. / V. I. Manukyan - K.: Istina, 2010. - 477 s.

3. De Sal'via M. Precedenty Evropeyskogo Suda po pravam cheloveka. Rukovodyaschie principy sudebnoy praktiki, otnosyaschiesya k Evropeyskoy konvencii o zaschite prav cheloveka i osnovnih svobod. Sudebnaya praktika s 1960 po 2002 g. / M. De Sal'via. - SPb. : Izdatel'stvo «Yuridicheskiy centr Press», 2004. - 1240 s.

4. Sultanov A. O probleme motivirovannosti sudebnyh aktov, cherez prizmu Postanovleniy Evropeyskogo Suda po pravam cheloveka / A. R. Sultanov // Arbitrazhnoe pravo. - 2007. - № №178 (1952)./ http://www.yurclub. $\mathrm{ru} /$ docs/arbitration/.
5. Yarkov V. Kommentariy k APK RF / pod. red.. V. V. Yarkova. M.: BEK, 2003.

6. Polyakov Yu. K voprosu o nezavisimosti suda / Yu. N. Polyakov // «Gosudarstvo i pravo». - 2000. - №10. - S. 85.

7. Vikut M. Zakonnost' i obosnovannost' aktov socialisticheskogo pravosudiya kak glavnoe uslovie vypolneniya zadach grazhdanskogo sudoproizvodstva / M. A. Vikut// Civilisticheskie problemy pravovogo statusa lichnosti v socialisticheskom obschestve . - Saratov, 1982. - S. 124.

8. Ponomarenko V. A. Motivirovannost' sudebnogo resheniya $\mathrm{v}$ grazhdanskom i arbitrazhnom processe : avtoref. diss.. kand.. yurid. nauk. Moskva, 2007.

9. Fil'chenko I. G. Processual'nye garantii prinyatiya obosnovannogo sudebnogo resheniya $\mathrm{v}$ grazhdanskom processe: avtoref. diss.. kand.. yurid. nauk. Voronezh, 2010.

10. Lebed' K. Resheniya arbitrazhnogo suda / K. A. Lebed'. - M., 2005. - 116 s.

11. Zagaynova S. Sudebnye akty v mehanizme realizacii sudebnoy vlasti $v$ grazhdanskom $i$ arbitrazhnom processe // S. K. Zagaynova. - M. : Volters Kluver. -2007. - 400 s.

12. Tolochko A. N. Rol' motivirovki v obespechenii zakonnosti, obosnovannosti i spravedlivosti aktov socialisticheskogo pravosudiya, vynosimyh sudom pervoy instancii po ugolovnym delam: avtoref. diss.. kand.. yurid. nauk, Har'kov, 1985.

13. Afanas'ev S. Pravo na spravedlivoe sudebnoe razbiratel'stvo: teoretiko-prakticheskoe issledovanie vliyaniya Evropeyskoy Konvencii o zaschite prav cheloveka i osnovnyh svobod na rossiyskoe grazhdanskoe sudoproizvodstvo: avtoref. dis.. doktora yurid. nauk, Saratov, 2010.

14. Kaplina O. I. Pravozastosovne tlumachennya sudom norm kriminal'no-procesual'nogo prava: avtoref. dis.. doktora yuridichnih nauk, Harkiv, 2009. 